\title{
COMPARTIMENTAÇÃO GEOMORFOLÓGICA E MORFOESTRUTURAL DA BACIA DO RIO CAPIBARIBE- MIRIM, PERNAMBUCO
}

\section{GEOMORPHOLOGICAL AND MORPHOSTRUCTURAL COMPARTMENTS OF RIO CAPIBARIBE-MIRIM WATERSHED, PERNAMBUCO}

\author{
Antônio Carlos de Barros Corrêa ${ }^{1}$ \\ dbiase2001@terra.com.br \\ Drielly Naamma Fonsêca ${ }^{2}$ \\ driellynaamma@gmail.com
}

\begin{abstract}
The following work proposes the identification of geomorphological compartments for the Capibaribe-Mirim river Watershed, based on the correlation of landforms and the several litho-types and geological structures of the area. A morphostructural analysis methodology, following the application of morphometric indexes to the landscape, was carried out in order to identify the major landform units. Those were coupled with the digital processing of lineaments, drainage network patterns and litho-structural data. This approach resulted in the identification of morphostructural units and their respective morphological sub-units.
\end{abstract}

Keywords: Morphostructural analysis, geomorphological mapping, Borborema highlands piedmont.

\footnotetext{
${ }^{1}$ Departamento de Ciências Geográficas, UFPE.

${ }^{2}$ Discente, Programa de Pós-Graduação em Geografia, UFPE.
} 


\section{RESUMO}

O presente trabalho propõe uma compartimentação geomorfológica para a bacia do rio Capibaribe-Mirim, a partir da correlação dos diferentes litotipos distribuídos sob as diversas formas de relevo. Utilizando o método de análise morfoestrutural alicerçados nos índices morfométricos, juntamente com a aplicação de fotolineamentos, do arranjo da rede de drenagem e dados litoestruturais. Esta abordagem permitiu a diferenciação do modelado na sua compartimentação morfoestrutural e suas subunidades morfológicas.

Palavras-chave: Análise morfoestrutural, mapeamento geomorfológico, Piemonte da Borborema.

\section{CONTEXTO DA PESQUISA}

Ao esquadrinhar as formas de relevo, a assimilação das particularidades morfológicas, bem como a dinâmica evolutiva da paisagem, o mapeamento das feições geomorfológicas e seu arranjo baseado nas configurações morfoestruturais são de suma importância na determinação de uma tipologia de formas e interpretação coerente do modelado. Partindo desse pressuposto, o processo evolutivo das formas é dado a partir da relação entre os arranjos tectônicos, ritmos eustáticos e bioclimáticos, diferindo dos modelos clássicos de evolução da paisagem pelo modo como o comportamento tectônico irá se associar com o tempo através dos processos denudacionais.

Assim, o propósito da presente pesquisa recai sobre a construção de uma síntese que reúna os diversos aspectos estruturais e morfológicos da bacia do rio Capibaribe-Mirim e entorno, em compartimentos geomórficos coerentes levando em consideração os dados referentes à altimetria, o arcabouço litoestratigráfico, além da origem tectônica das formas. Para tal, o estabelecimento das tipologias 
das unidades geomórficas da área de trabalho, optou-se por seguir as normas estabelecidas pela comissão de mapeamento da UGI - União Geográfica Internacional, descrita por Demek (1972), com a finalidade de obter um mapeamento em escala intermediária. O mapa final combina informações sintéticas sobre a morfografia, morfometria, gênese e idade das formas, a fim de estabelecer uma relação clara entre os materiais estruturadores e unidades morfológicas.

\section{MORFOTECTÔNICA NA PORÇÃO ORIENTAL DO NORDESTE DO BRASIL}

A área de estudo encontra-se no setor oriental da Província Borborema (figura 01.A), estruturadas sobre litologias do Pré-cambriano e por poucas bacias sedimentares, limitadas por estreitos divisores tabulares recobertos de rochas sedimentares, além das planícies costeiras. Compostas por rochas do Paleoproterozoico, Eo-Neoproterozoico e rochas deformadas do Neoproterozoico, cujo tectonismo foi em sua maioria gerado ou retrabalhado durante a junção PanAfricana (BEZERRA et al., 2008) ocorrida durante o Brasiliano, estando a área inserida dentro do contexto da Zona Transversal, que de acordo com Brito Neves et al. (2001a; 2001b) e Almeida et al. (2000) é a feição mais proeminente da Província Borborema, caracterizada pela presença de mega cisalhamentos dextrais - Zona de Cisalhamento Pernambuco (ZCPE) e Zona de Cisalhamento Patos (ZCPA) - extremamente importante no contexto tectonoestratigráfico regional. 


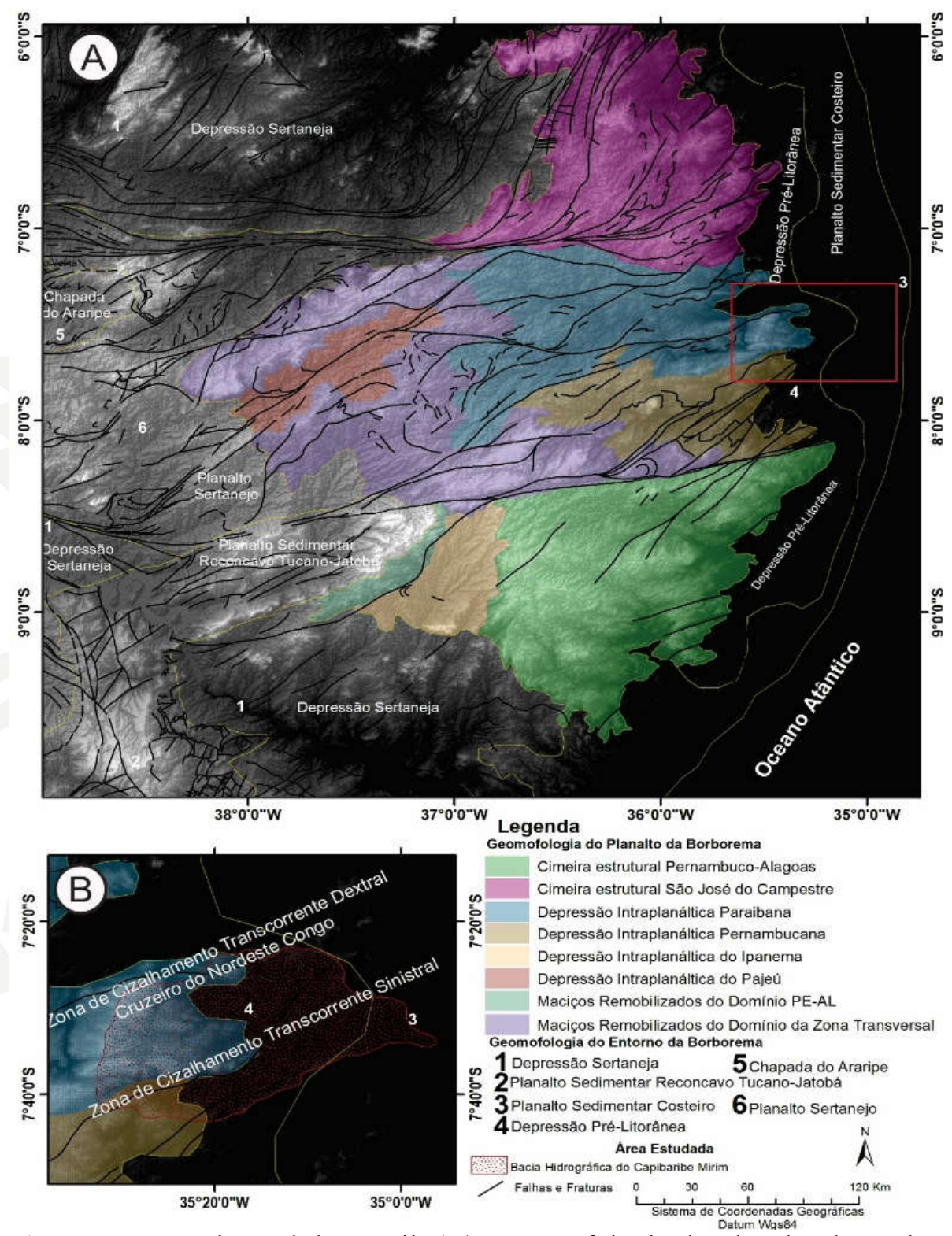

Figura 1: Margem continental do Brasil: (A) Geomorfologia do Planalto da Borborema e entorno com principais falhas e fraturas. (B) Área de estudo localizada entre o planalto, a Depressão Pré-Litorânea e Planalto Sedimentar Costeiro e principais zonas de cisalhamento.

Indexadores: Latindex, ISI, Google Academic 
A partir da separação do supercontinente Pangea durante o Mesozoico houve uma maior influência tectônica sobre os terrenos da Província Borborema, designados pelas fases rift e pós-rift. O principal rifteamento se deu durante o Aptiano $(\sim 140$ - $120 \mathrm{Ma}$ ), devido a reativação das zonas de cisalhamento durante o Neoproterozoico (CASTRO et al., 2012), responsáveis pelo desenvolvimento das bacias marginais e interioranas no contexto de margens passivas entre o Barrisiano até o Baremiano (FRANÇOLIN et al., 1994) e apresentando sequências deposicionais pós-rift a partir da abertura do Oceano Atlântico e evolução da margem passiva, apesar de menos intensa, os falhamentos continuaram sendo reativados (BEZERRA et al., 2008; 2011).

Desta maneira, as formas encontradas a partir da quebra da escarpa do Planalto da Borborema, estão estruturadas como teclas de piano (LIMA FILHO et al., 2005), uma vez que desníveis altimétricos em relação aos talvegues de mais de 100 metros são identificados para esta porção do planalto (BEZERRA et al., 2008; TAVARES, 2010; FONSÊCA, 2012). Para estes autores, as reativações póscretáceas são responsáveis por soerguimentos distintos e basculamentos, onde inúmeros falhamentos dinamizaram entalhes e orientaram a dissecação e deposição.

Define-se como Planalto da Borborema o setor das terras altas acima da isoípsa de 200 metros, situado ao norte do rio São Francisco e estruturado em uma grande variedade litológica correspondente aos maciços cristalinos do Arqueano que foram remobilizados, além das intrusões plutônicas do Neoproterozoico sin-tardia 
e pós-orogênica (CORRÊA et al., 2010). Em seu setor oriental, o planalto é reconhecido a partir da ruptura da escarpa e os patamares rebaixados do piemonte em direção à costa (figura 01.B). A oeste do domo, seu limite se dá pela ruptura com a depressão sertaneja na forma de um semicírculo de terras baixas semiáridas, separadas do topo do planalto através de relevos escarpados, ressaltando os controles litoestruturais.

Dados gravimétricos e magnetométricos para o estudo isostático e das causas do magmatismo cenozoico na Província Borborema, o soerguimento do Planalto da Borborema estaria atrelado ao magmatismo continental gerado pela convecção da borda impulsionada, que teria aprisionado o magma entre o limite da litosfera e da crosta continental (OLIVEIRA, 2008), gerando uma assimilação subsuperficial de magma (underplatting). Este modelo corrobora com os estudos de Matsumoto (1973) explicando as deformações recentes na região, assim como o surgimento do planalto posterior ao Cretáceo, conforme sugerido por Domingues (1961). Ademais, idades obtidas por Traço de Fissão de Apatita - agrupadas em dois grupos de 90 - $100 \mathrm{Ma}$ e $20 \mathrm{Ma}$-, sugerem duas fases de soerguimento (MORAIS NETO et al., 2009) associadas a abertura do Oceano Atlântico e ao magmatismo continental, respectivamente, também propostos pelo modelo de Oliveira (2008).

\section{MATERIAIS E MÉTODOS}

A combinação do elemento "estável", ou seja, da estrutura geológica pré-existente juntamente com o elemento dinâmico que modelam a superfície foram definidos por Gerasimov e Mescheriov (1968) como a morfoestrutura da paisagem, termo 
utilizado em análises de caráter regional, onde se busca relacionar o controle litoestrutural subjacente ao arranjo das feições morfológicas existentes (SAADI, 1991). Corresponde também a feições topográficas maiores coincidentes com a expressão estrutural e litológica, podendo ainda ser formadas por movimentações tectônicas produzidas pela interação de processos endógenos e exógenos, cujo elemento guia para o estabelecimento desta correlação é a forma de relevo predominante (BATES e JACKSON, 1987).

Portanto, de acordo com as premissas acima elencadas, a tentativa de compartimentação morfoestrutural e morfológica da bacia do rio CapibaribeMirim utilizou, além da correlação entre as características litoestruturais, o comportamento da rede de drenagem. A definição dos diferentes padrões de drenagem foi elaborada a partir da análise qualitativa e quantitativa dos padrões geométricos de organização espacial dos canais, conforme proposta elaborada por Summerfield (1991) que, ao atrelar à análise aos processos morfotectônicos e morfoestruturais, exprime a importante contribuição das alterações de nível de base à capacidade dos canais fluviais se reorganizarem assumindo padrões morfológicos peculiares (SCHUMM, 1977).

A rede de drenagem da área foi adquirida através da digitalização da base planimétrica da SUDENE em escala de 1:25.000, associada à drenagem extraída dos dados SRTM (Shuttle Radar Topography Mission) em resolução espacial de 30 metros disponibilizada no site da USGS (United States Geological Survey), com a finalidade de identificar os principais padrões de drenagem e direções dos 
canais, conforme proposta de Christofoletti $(1981 ; 1983)$. Estes dados também foram utilizados para a extração de fotolineamentos das formas lineares topográficas (ETCHEBEHERE et al., 2007; LIU, 1984), com o intuito de tentar representar as descontinuidades estruturais.

No que diz respeito ao arcabouço litoestrutural foi utilizada a base em escala de 1:500.000 do Projeto Geologia e Recursos Minerais do Estado de Pernambuco, desenvolvido por Gomes e Santos (2001). Atrelado a esses dados, a modelagem digital do terreno foi elabora a partir dos dados SRTM, de onde foram extraídas as curvas de nível e elaboração do relevo sombreado no software ArcGIS 10.1, visando ressaltar as morfoestruturas e delimitar em caráter regional das feições geomórficas da área estudada.

\section{RESULTADOS E DISCUSSÕES}

\section{Morfoestruturas da bacia do rio Capibaribe-Mirim}

Inicialmente, o contexto geomorfológico da área pode ser hierarquizado através de uma proposta de subdivisão geotectônica e, secundariamente, litoestratigráfica. As unidades de maior táxon estão vinculadas aos limites definidos entre a bacia sedimentar marginal e as litologias metamórficas e plutônicas dos complexos precambrianos, aos processos deposicionais contemporâneos ao longo da linha de costas e os cursos de drenagem, além das respostas dos estoques litológicos aos processos denudacionais. As estruturas litológicas também se manifestam na delimitação dos conjuntos de formas, definindo subespaços ora mais elevados, com conservação parcial das superfícies de cimeira, ora mais dissecados e 
topograficamente mais rebaixados, muitas vezes englobando mais de um domínio litológico sob a mesma tipologia morfoestrutural.

Os agrupamentos de formas podem ser separados devido ao seu predomínio na estruturação da paisagem, a exemplo dos baixos planaltos sedimentares entre a ZCPE e ZCPA. Outros níveis de expressão espacial das formas se expressam sob o controle estrutural, sendo discerníveis em escalas de maior detalhe, constituindo as unidades morfológicas, sobretudo no caso dos complexos precambrianos com maior variabilidade litológica e ocorrência de zonas de cisalhamento reativadas (BEZERRA et al., 2008). Tais controles produzem morfologias locais de maior destaque topográfico sob a forma de maciços estruturais, linhas de cristas e escarpas.

Assim, para a bacia do rio Capibaribe-Mirim foram definidos quatro domínios morfoestruturais que correspondem ao primeiro táxon hierárquico do relevo: as Planícies Fluviais, o Planalto Sedimentar Litorâneo, o Piemonte da Borborema e o próprio Planalto da Borborema, estando estes domínios subdivididos em subdomínios em função dos conjuntos litoestruturais dominantes.

O domínio das planícies (Figura 02.D) é caracterizado por unidades deposicionais de idade quaternária resultando em modelados planos de acumulação. Ocorrem de forma longitudinal e descontínua às margens dos principais drenos da área de estudo, ou seja, do rio Capibaribe-Mirim e Siriji, que assim como os demais drenos, se direcionam perpendicularmente à linha de costa por meio de 
acumulação e coalescência de cordões litorâneos. O planalto sedimentar litorâneo ocorre na área entre a ZCPE e ZCPA estabelecido sobre as litologias da bacia Paraíba e, principalmente, sobre o capeamento cenozoico da mesma, atrelado aos sedimentos da Formação Barreiras do Neógeno. A estruturação geral deste baixo planalto pode ser observada a partir da disposição homoclinal do preenchimento da bacia Paraíba apresentando flexura em direção à costa. Nesta unidade, a evolução do relevo se dá devido a erosão regressiva das cabeceiras, responsável pelo entalhe ativo dos sedimentos incoesos que compõem o substrato desta unidade, estando em alguns casos vales mais entrincheirados, as formações mesozoicas subjacentes.

Morfologicamente é dominada por divisores mais ou menos amplos e tabulares (Figura 02.D e 02.E), dissecados por vales consequentes de primeira ordem que normalmente confluem paralelamente para o coletor principal, resultado da adaptação às estruturas lineares que interceptam transversalmente a linha de costa, acompanhando a direção preferencial das zonas de cisalhamento. Ainda sobre esta unidade morfológica, percebe-se que o grau de dissecação também aumenta à medida que se direciona à costa, isolando e estreitando gradualmente as feições tabulares, rebaixando-os.

O domínio do Piemonte da Borborema pode ser dividido em virtude dos contextos litoestruturais aos quais se sobrepõe. Morfologicamente é definido por ser um domínio de formas convexas, em diversos graus de isolamento e/ou agrupamento, com altitudes abaixo dos 200 metros e densamente seccionada pela rede de 
drenagem de morfologia ora dendrítica, ora condicionada pelas estruturas lineares subjacentes, conferindo trechos de canais retilíneos, mudanças bruscas na direção em ângulo reto e quebras de patamares que dão origem a corredeiras.

Sem uma aparente solução de continuidade, o piemonte se divide em três subunidades, sem a presença de coberturas terciárias, sendo os pacotes compostos por sedimentos coluviais e do material intemperizado in situ. A subdivisão deste domínio se dá através do controle litoestrutural que secciona no Hemi-Gráben do rio Água Torta (Figura 02.A; 02.C; 02.F), na porção norte da bacia limitadas por estruturas de direção SW-NE com diferenças altimétricas de 200 metros em relação aos blocos elevados.

Ao sul da bacia encontra-se o Hemi-Gráben do rio Siriji (Figura 02.B; 02.C; 02F; 02.G), onde também há um contato abrupto com diferenças altimétricas de 200 metros, ao passo que na borda sul esta mudança abrupta não é observada, contando apenas com um divisor rebaixado entre o rio Siriji e o rio Tracunhaém, ambos apresentando um direcionamento preferencial WSW-ENE. O terceiro subcompartimento descrito se encontra na porção central da bacia, denominada de Superfície Dissecada em Cristas e Vales, caracterizada por uma estrutura de blocos falhados sob a influência litológica das zonas de cisalhamento (Figura 02.C; 02.E). Tal compartimento reflete diferenças estruturais entre si, apresentando a linearidade das formas em cristas, gradativamente mais baixas em direção às costas. Estas características podem ser interpretadas como dois blocos individuais subdivididos e independentes entre si, no que tange aos processos 
erosivos, variantes de acordo com a estruturação superficial da paisagem e/ou composição litológica de cada bloco. Estas afirmações corroboram até certo ponto com o modelo estabelecido para área vizinha do Gráben do Cariatá, descrito por Bezerra et al. (2008) e Tavares et al. (2014), marcadas pela estruturação regional em blocos falhados, soerguidos e reestruturados em diferentes cotas altimétricas.

Já na área do domínio do Planalto da Borborema, correspondente ao conjunto de feições acima dos 300 metros e que, na área, assume um basculamento perpendicular à linha de costa, pode ser subdivido em três subcompartimentos, sendo o primeiro deles a Superfície de Cimeira da bacia que abrange as áreas de cabeceira das drenagens do rio Capibaribe-Mirim e Siriji, em cotas altimétricas que variam de 500 a 690 metros (Figura 02.B; 02.G), apresentando relevo escarpados e encostas abruptas nos seus limites, em litologias de alto grau de metamorfismo e plútons associados às zonas de cisalhamento.

Imediatamente à leste do subcompartimento de cimeira, separada deste por falhas normais de direção N-S, a Superfície Dissecada com basculamento W-E está inserida em cotas altimétricas que variam entre 450 e 300 metros, a depender do nível de incisão da rede de drenagem. Litologicamente é semelhante ao compartimento de cimeira, porém, devido ao maior adensamento de zonas de cisalhamentos e fraturamentos subordinados aos lineamentos principais, faz com que este compartimento exiba níveis topográficos em degraus, relacionados à erosão diferencial e à subordinação do relevo às estruturas geológicas reativadas ou superimpostas (Figura 02.A; 02.B; 02.G). 

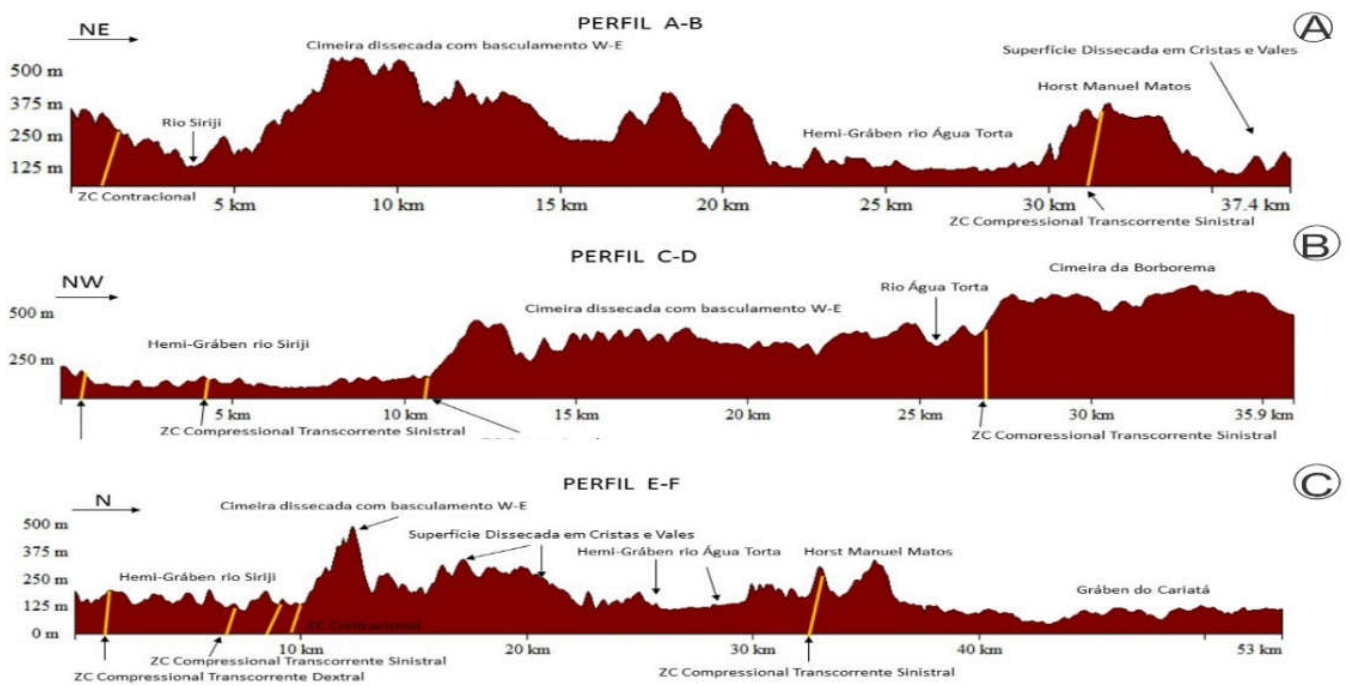

(C)
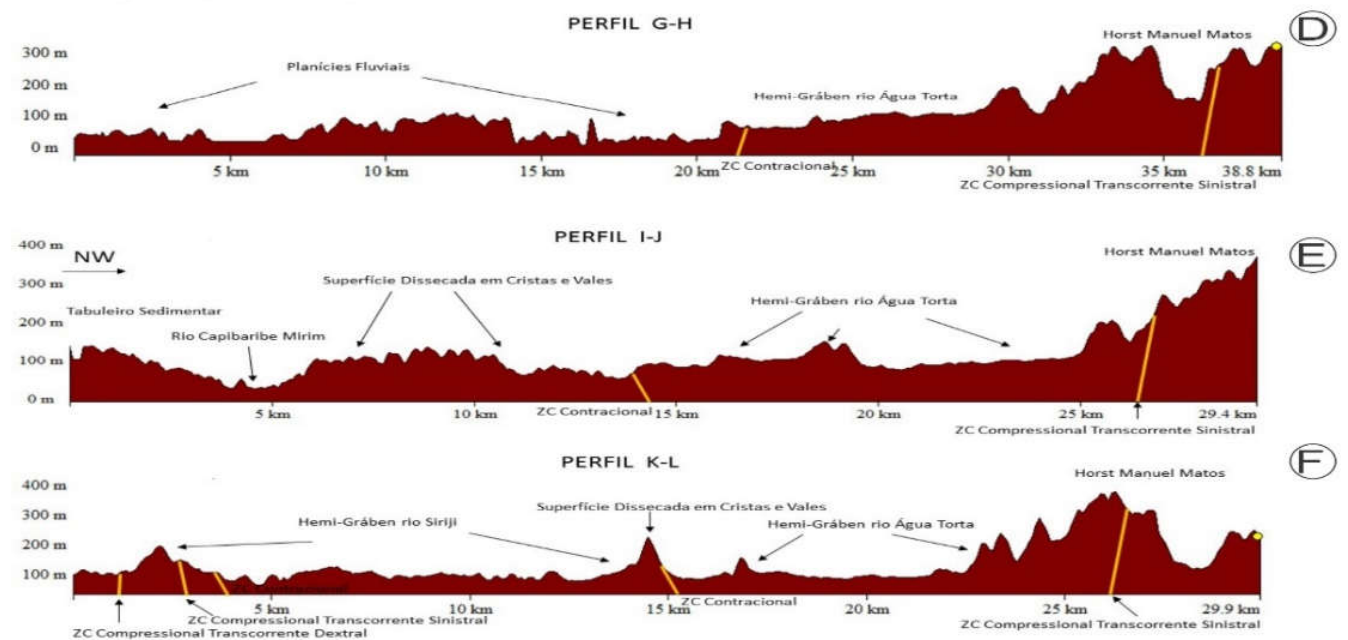

(F)

PERFIL M-N

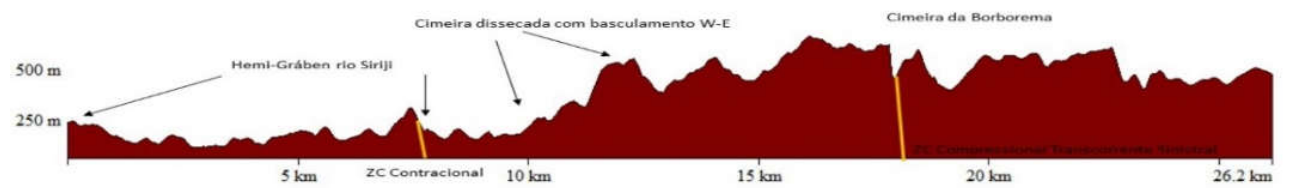

Figura 2: Transectos da BHCM contendo principais compartimentos morfoestruturais, zonas de cisalhamentos.

Indexadores: Latindex, ISI, Google Academic 
Já o ultimo subcompartimento, o Horst Manuel Mattos, atua como divisor entre a área estudada e o Gráben do Cariatá ao norte (Figura 02.C), estruturado por uma falha transcorrente dextral (falha de Camutanga) e caracterizado por uma unidade metassedimentar e metavulcânica típica do Terreno Alto Moxotó (BRITO NEVES et al., 2004), que possui um grau de metamorfismo médio a forte, sendo extremamente migmatizada, possuindo também ortognaisses e granodioritos retrabalhados no Mesoproterozoico e Neoproterozoico. Deste modo, há um forte controle das unidades litoestruturais sobre o recuo das escarpas neste setor, exibindo longas cristas e diferenças altimétricas entre topo e base superiores a 100 metros (Figura 02.A; 02.D). Tal arranjo litoestrutural também é responsável pela manutenção deste compartimento como um alto estrutural.

\section{Compartimentação Geomorfológica}

Os domínios morfoestruturais se desdobram em unidades geomorfológicas, nas quais os atributos da paisagem, ou seja, litologia, solo, declividade, entre outros, se relacionam e se diferenciam do entorno, passando a constituir uma categoria de relevo discreta. Assim, a construção do mapa é feita de uma constante reavaliação dos limites e propriedades dos compartimentos, até se obter o mapeamento final (figura 03). Os padrões do relevo foram definidos mediante análise morfológica e morfométrica das unidades de formas predominantes para cada agrupamento estabelecido para o segundo táxon da classificação.

As superfícies de cimeira correspondem aos níveis mais elevados do Planalto da Borborema, em cotas acima dos 300 metros, estando divididas em Cimeira 
rochosa, situada acima dos 500 metros onde há a exposição das rochas plutônicas encaixadas nas zonas de cisalhamento, mais resistentes ao intemperismo, conferindo a essas áreas, relevos mais aguçados. Em cotas entre 500 e 400 metros denomina-se as Cimeiras com cobertura elúvio/coluvial que apresentam formas mais suavemente onduladas (Figura 04.A), devido à existência de um manto de intemperismo fracamente dissecado controlando a morfologia. Tal característica advém do intemperismo da rocha in situ, enquanto que nas áreas situadas ao longo da quebra da escarpa do Planalto da Borborema, há a ocorrência de cobertura coluvial aprisionada nos espaços de acomodação criados pelos knick-points locais.

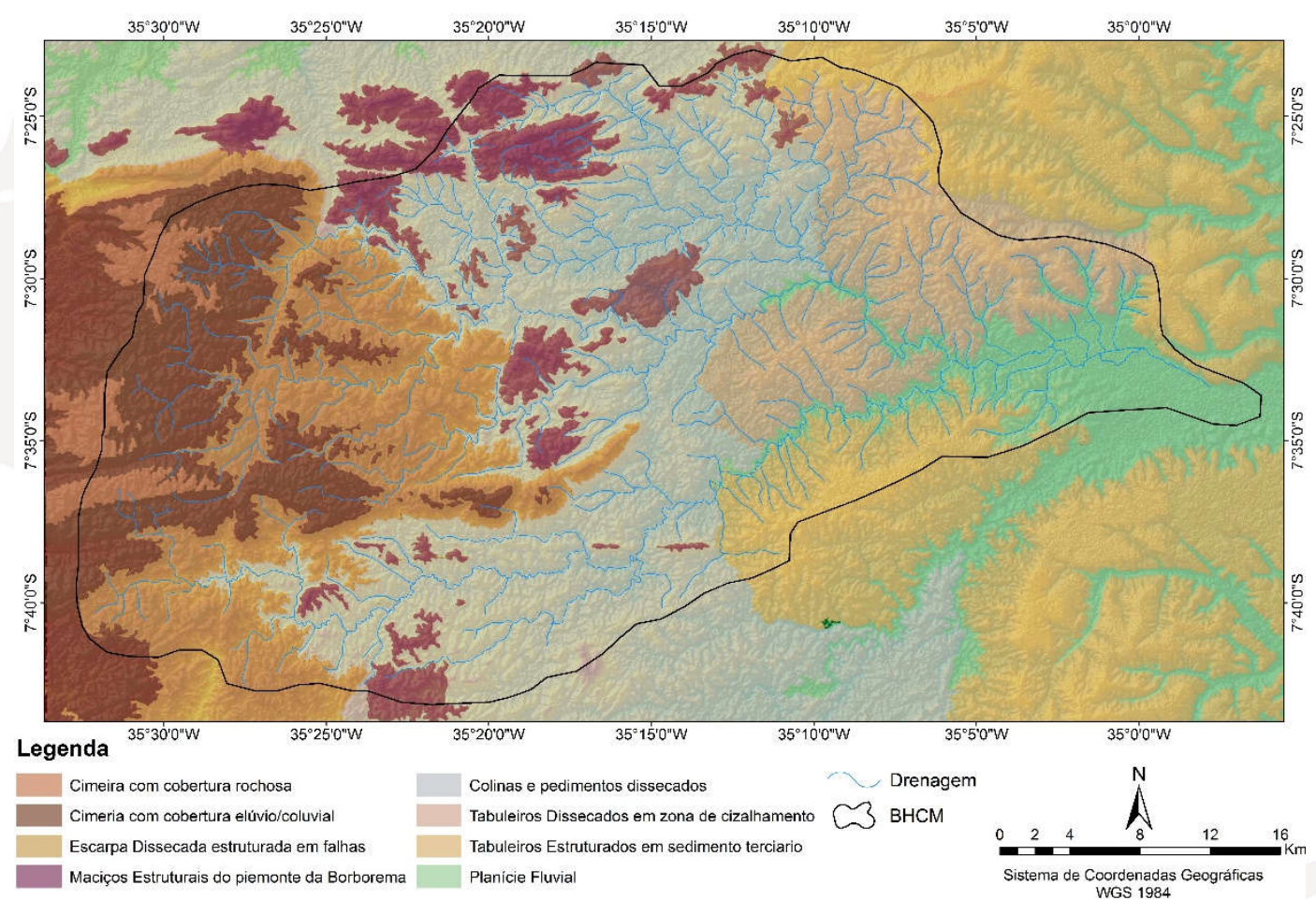

Figura 3: Compartimentação geomorfológica da bacia do rio Capibaribe-Mirim. 
Já as Escarpas dissecadas estruturadas em falhas constituem um testemunho do recuo erosivo da descontinuidade topográfica entre os compartimentos mais elevados do Planalto da Borborema e as áreas rebaixadas imediatamente a leste pertencentes ao Piemonte da Borborema. Caracterizadas por áreas elevadas que sofreram a ação do intemperismo e foram relativamente rebaixadas aos níveis atuais (Figura 04.A), devido à erosão remontante. A partir da concepção tectonoestrutural, esta escarpa seria uma escarpa da falha recuada devido ao soerguimento de um bloco em relação ao adjacente. Sua maior dissecação se dá devido ao gradiente gravitacional criado pelo desnivelamento altimétrico que propiciou a regressão e o rebaixamento da encosta, deixando testemunhos estruturais da antiga linha do front escarpado da Borborema sob a forma de divisores festonados.

Se expressando na paisagem como domos estruturais dissecados, os Maciços estruturais estão localizados por toda extensão da área, possuindo cotas altimétricas que variam de 300 a 350 metros e que, geralmente, são marcados por zonas de cisalhamento e falhas normais. Litologicamente estão associados a rochas intrusivas, atuando como relevos estruturais (Figura 04. B) e residuais no que tange a erosão diferencial, como relevos do tipo inselbergs de piemonte antecedendo as encostas do Planalto da Borborema.

As Colinas e pedimentos dissecados ocupam grande parcela da área da bacia, no domínio do Piemonte da Borborema, tratando-se de uma área dominada pelo relevo pluriconvexo intercalados por pedimentos. As superfícies colinosas 
apresentam feições mais ou menos individualizadas de topos planos a arredondados e vertentes convexo-côncava (Figura 04.A) com cabeceiras de drenagem em anfiteatro, típicas do relevo cristalino sob o domínio morfoclimático tropical úmido. Os processos de intemperismo são predominantes, além da ação intensa da rede de drenagem (Figura 05.B), provocando o recuo das vertentes pelo escoamento superficial que por vezes forma rampas de colúvio em espaços de acomodação criados pelo controle estrutural, variantes de dezenas a centenas de metros.

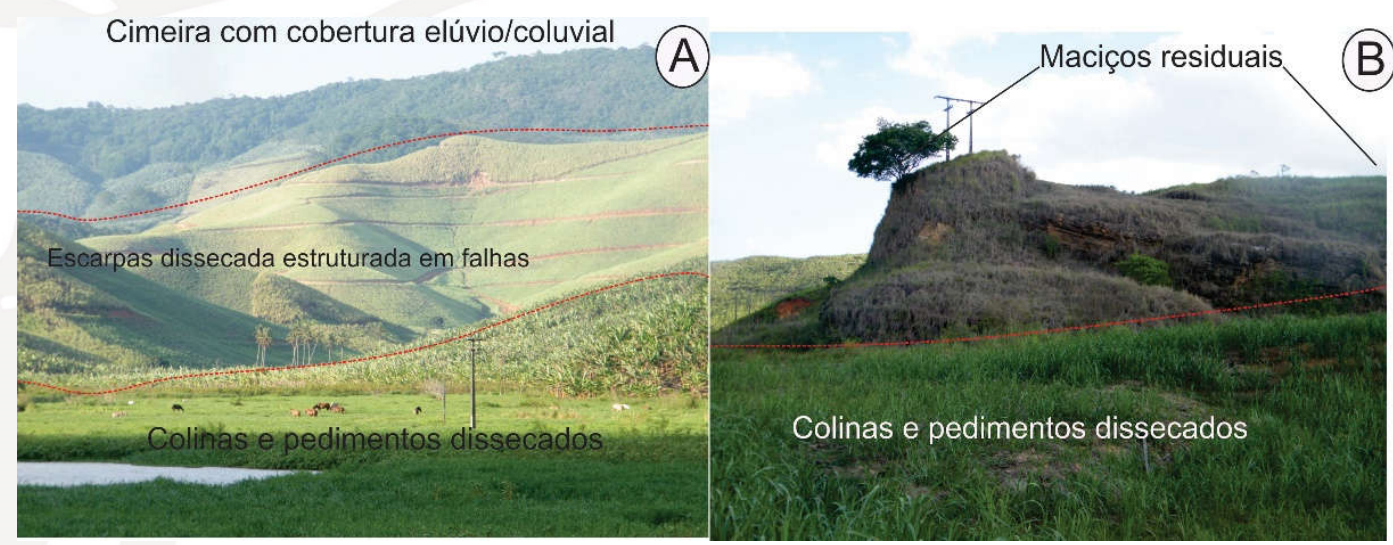

Figura 4: Principais compartimentos da bacia do rio Capibaribe-Mirim: (A) Cimeiras com cobertura elúvio/coluvial e escarpas dissecada estruturada em falhas do Planalto da Borborema; e Colinas e pedimentos dissecados; (B) Maciços estruturais e Colinas e pedimentos dissecados.

Dentro do domínio do Planalto Sedimentar Litorâneo, no contexto da bacia do rio Capibaribe-Mirim, foi possível subdividir em duas unidades morfológicas: a primeira denominada como Tabuleiros dissecados em zona de cisalhamento, uma vez que estão situados em uma área sob a influência de uma zona de cisalhamento compressional no setor nordeste da bacia. Apresenta cotas altimétricas acima dos 100 metros, formando cornijas sobre alvéolos 
semicirculares esculpidos pela rede de drenagem instalada nas falhas e fraturas subordinas ao cisalhamento principal.

Os sedimentos encontrados nestes tabuleiros apresentam níveis de ferricrete em superfície, vindo a corroborar com a ideia de quebra e soerguimento de blocos distintos, e consequente rebaixamento do lençol freático. Ademais, devido a intensa dissecação desta unidade, um possível capeamento sedimentar da Formação Barreiras foi evacuado para o fundo das drenagens ou retrabalhado como sedimentos coluviais.
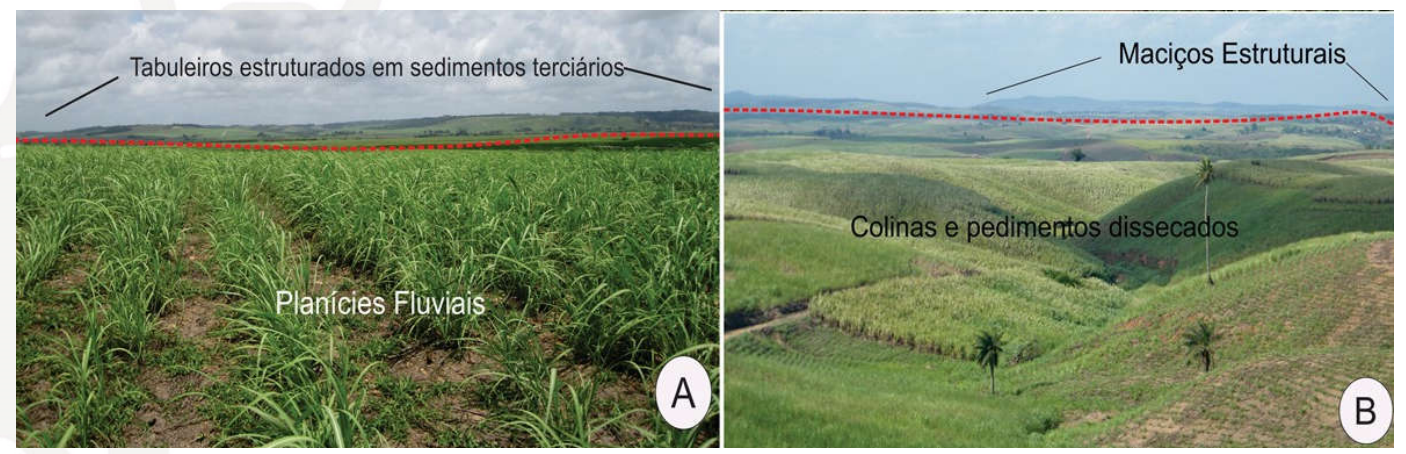

Figura 5: Principais compartimentos da bacia do rio Capibaribe-Mirim: (A) Tabuleiros estruturados em sedimentos terciários e morfologia das Planícies fluviais; (B) Maciços estruturais e Colinas e pedimentos dissecados do Piemonte da Borborema.

Enquanto que os Tabuleiros estruturados em sedimentos terciários, localizados nos setores nordeste e sudeste da bacia exercendo a função de baixo divisores entre a área de estudo e as bacias vizinhas, apresentam forma tabular alongadas (Figura 05.A) e estão estruturados pelos sedimentos da Formação Barreiras. Esta unidade possui uma direção geral SW-NE, obedecendo o trend regional, cuja 
drenagem se apresenta bastante encaixada, com vertentes abruptas e altitudes que variam de 150 a 170 metros.

Por fim, as unidades morfológicas das Planícies fluviais apresentam um conjunto de padrões planos separados em níveis altimétricos de 10 e 15 metros em direção ao continente, caracterizando os modelados deposicionais de origem fluvial em diversos graus de continuidade longitudinal (Figura 05.A) e extensão transversal em relação aos canais de drenagem.

\section{CONSIDERAÇÕES FINAIS}

A principal contribuição do artigo é a delimitação dos compartimentos morfoestruturais e geomorfológicos da bacia do rio Capibaribe-Mirim que reflete de forma clara a influência tectônica e litoestratigráfica herdadas após a abertura final do Oceano Atlântico durante o Cretáceo Superior, devido a ocorrência do rifteamento na margem do continente, além da manutenção da flexura da borda do mesmo ao longo do Cenozoico. Deste modo, os controles estruturais orientam as formas e a drenagem de acordo com as principais zonas de fraqueza, acompanhando as zonas de cisalhamento pré-cambrianas reativadas e que possuem direções preferenciais E-W, WNW-ESE. Este controle, por consequência, confere à paisagem geomorfológica da bacia do rio CapibaribeMirim formas características, como os maciços estruturais, as linhas de cristas e escarpas, além das áreas de acumulação de planície com características longitudinais e descontínuas. 
Outrossim, constatou-se que o modelado se desenvolve sob o controle da erosão regressiva, como no caso dos sedimentos incoesos da Formação Barreiras, predominando uma morfologia de divisores tabulares, ora amplos ora estreitos. Observa-se ainda que à medida que aumenta o grau de dissecação, há uma maior fragmentação do baixo planalto tabular, reduzindo a morfologias colinosas muitas vezes confundidas com as feições cristalinas no que tange à altitude, demonstrando que os sedimentos da bacia Paraíba foram soerguidos devido à manutenção da flexura da borda continental ao longo do Neógeno.

Em suma, as unidades morfoestruturais se desdobram em unidades morfológicas, apresentando uma relação geométrica entre os interflúvios, altimetria e largura média dos divisores. Esta conjuntura de formas deixa evidente a integração entre as litoestruturas e os processos atuantes, conferindo a esses padrões geomorfológicos particularidades que estão estritamente associados aos processos superficiais.

\section{REFERÊNCIAS BIBLIOGRÁFICAS}

ALMEIDA, F. F. M.; BRITO NEVES, B. B.; CARNEIRO, C. D. R. The origin and evolution of the South American platform. Earth-Science Reviews, v. 50, p. 77-111, 2000.

BATES, R. L. \& JACKSON, J. A. Glossary of Geology. Virginia: Geological Institute, Alexandria,1987, 788p.

BEZERRA, F.H.R.; BRITO NEVES, B.B.; CORRÊA, A.C.B.; BARRETO, A.M.F.; SUGUIO. K. Late Pleistocene tectonic-geomorphological development within a passive margin - The Cariatá trough, northeastern Brazil. Geomorphology. v.97, p.555-582, 2008 . 
BEZERRA, F. H. R.; NASCIMENTO, A. F.; FERREIRA, J. M.; NOGUEIRA, F. C.; FUCK, R. A.; BRITO NEVES, B. B.; SOUSA, M. O. L. Review of active faults in the Borborema Province, intraplate South America integration of seismological and paleoseismological data. Tectonophysics, v.510, p.269-290, 2011.

BRITO NEVES, B. B.; CAMPOS NETO, M. C.; VAN SCHMUS, W. R.; SANTOS, E. J. O sistema Pajeú-Paraíba e o maciço São José do Campestre no leste da Borborema. Revista Brasileira de Geociências, v. 31, p. 1-15, 2001a.

BRITO NEVES, B. B.; CAMPOS NETO, M. C.; VAN SCHMUS, W. R.; FERNANDES, T. M. G.; SOUZA, S. O. O terreno Alto Moxotó no leste da Paraíba (maciço Caldas Brandão). Revista Brasileira de Geociências, v. 31, p. 16-31, 2001 b.

BRITO NEVES, B. B.; RICCOMINI, C.; FERNANDES, T. M. G.; SANT'ANNA, L. G. O sistema trafogênico terciário do saliente oriental nordestino na Paraíba: um legado Proterozóico. Revista Brasileira de Geociências, v.34, n.1, p.127-134, 2004.

CASTRO, D. L.; BEZERRA, F. H. R.; SOUSA, M. O. L.; FUCK, R. A. Influence of Neoproterozoic tectonic fabric in the origin of the Potiguar Basin, northeastern Brazil and links with West Africa based on gravity and magnetic data. Journal of Geodynamics, v.54, p.29-42, 2012.

CHRISTOFOLETTI, A. A significância da densidade de Drenagem para as análises geomorfológicas. Boletim de Geografia Teorética, Rio Claro, v.13, p.27-53, 1983.

CHRISTOFOLETTI, A. A variabilidade espacial e temporal da densidade de drenagem. Notícia Geomorfológica, v.21, n.42, p.3-22, 1981.

CORRÊA, A.C.B; TAVARES, B.A.C; MONTEIRO, K.A; CAVALCANTI, L.C.S; LIRA, D.R. Megageomorfologia e Morfoestrutura do Planalto da Borborema. Revista do Instituto Geológico, São Paulo, v. 31, n.1/2, p.35-52, 2010.

DEMEK, J. (Ed) Manual of detailed geomorphological mapping. Praga: Comm. Goomorph. Surv. Mapping. IGU, 1972. 368p.

DOMINGUES, A. J. P. Aspectos físicos do Meio Norte e do Nordeste. In: IBGE. Paisagens do Brasil, p.171-182, 1961. 
ETCHEBEHERE, M. L. C.; SAAD, A. R.; FULFARO, V. J. Análise da bacia aplicada à prospecção de água subterrânea no planalto ocidental paulista, SP. Geociências, São Paulo, UNESP, v.26, n.3, p.229-247, 2007.

FONSÊCA, D. N. Reconstrução da paisagem geomorfológica através da assinatura geoquímica dos eventos deposicionais da bacia do rio Capibaribe-Mirim, Pernambuco. Recife, PE. 167f. 2012. Dissertação de Mestrado, Universidade Federal de Pernambuco, 2012.

FRANÇOLIN, J. B. L.; COBBOLD, P. R.; SZATMARI, P. Faulting in the Early Cretaceous Rio do Peixe basin (NE Brasil) and its significance for the opening of the Atlantic. Journal of structural geology, v. 16, p. 647-661, 1994.

GERAMISOV, I. P. \& MESCHEIROV, J. A. Morphostructure. In: FAIRBRIDGE, R. W. (Ed.). The Encyclopedia of Geomorphology - Encyclopedia of Earth Sciences. Pennsylvania - Dowden: Hutchinson e Koss Inc., 1968, p.731-732.

GOMES, H. A.; SANTOS, E. J. dos. Mapa Geológico do Estado de Pernambuco. In: GOMES, H. A. (Org.) Geologia e Recursos Minerais do Estado de Pernambuco, Escala 1:500.000. Brasília, CPRM - Serviço Geológico do Brasil, texto explicativo, 198p., mapas, 2001.

LIMA FILHO, M. F.; BARBOSA, J. A.; NEUMANN, V. H.; SOUZA, E. M. Evolução estrutural comparativa da Bacia Pernambuco e da Bacia da Paraíba. In: SIMPÓSIO NACIONAL DE ESTUDOS TECTÔNICOS, 5, Curitiba. Boletim de resumos Expandidos. Curitiba, 2005, p.45-47.

LIU, C. C. Análise estrutural de lineamentos em imagens de sensoriamento remoto: aplicação no Estado do Rio de Janeiro. São Paulo, SP. 1984. 175f. Tese de Doutorado, Universidade de São Paulo, 1984.

MATSUMOTO, E. The landforms and some geomorphic problems in the eastern part of the Brazilian Northeast. Tokyo Geography Papers, v.17, p.73-85, 1973.

MORAIS NETO, J. M.; HEGARTY, K. A.; KARNER, G. D.; ALKMIM, F. F. Timing and mechanisms for the generation and modification of the anomalus Topography of the Borborema Province, northeastern Brazil. Marine and Petroleum Geology, v.26, n.7, p.1070-1086, 2009. 
SAADI, A. Ensaio sobre a morfotectônica de Minas Gerais: tensões intraplaca, descontinuidades crustais e morfogênese. 300f. Tese Professor Titular, Universidade Federal de Minas Gerais, 1991.

SHUMM, S. A. The Fluvial System. John Willey \& Sons Press. Colorado. 1977. 337p.

SUMMERFIELD, M. A. Global Geomorphology. New York: John Willey \& Sons. $1991.537 \mathrm{p}$.

TAVARES, B. A. C. A participação da morfoestrutura na gênese da compartimentação geomorfológica do gráben do Cariatá, Paraíba. Recife, PE. 137f. 2010. Dissertação de Mestrado, Universidade Federal de Pernambuco, 2010.

TAVARES, B. A. C.; CORREAA, A. C. B.; LIRA, D. R.; CAVAlCANTI, L. C. S. Compartimentação geomorfológica e morfotectônica do Gráben do Cariatá, Paraíba, a partir de imageamento remoto. Revista Brasileira de Geomorfologia, v.15, n.4, p.523$538,2014$. 